\title{
Perancangan al-Qur'an Player untuk Tunanetra menggunakan Mikrokontroler dan DFPlayer
}

\section{Design of al-Qur'an Player for Blind People using Microcontroller and DFPlayer}

\author{
Hidayat $^{1 *}$, L Nurjanah ${ }^{2}$ \\ 1)Program Studi Teknik Komputer, Fakultas Teknik dan Ilmu Komputer, Universitas Komputer Indonesia \\ Jl. Dipati Ukur No. 112 - 116, Bandung, Indonesia 40132 \\ 2)Program Studi Sistem Komputer, Fakultas Teknik dan Ilmu Komputer, Universitas Komputer Indonesia \\ Jl. Dipati Ukur No. 112 - 116, Bandung, Indonesia 40132 \\ *email:hidayat@email.unikom.ac.id
}

\begin{abstract}
The limited number of electronic devices for blind people that can assist them in learning and memorizing the Koran encourages researchers to design electronic devices for the al-Qur'an Player for blind people. The electronic device is designed by utilizing the ATMega128 microcontroller as the main controller unit and the DFPlayer module as a decoder to convert digital files into audio. All suras and verses of the al-Qur'an in mp3 format are stored on the memory card that will be read by the DFPlayer module. This al-Qur'an player is expected to make it easier for blind people to learn the pronunciation of the al-Qur'an properly and correctly.
\end{abstract}

Keywords - al-Qur'an Player; Blind people; DFPlayer mini; Microncontroller ATMega128

\begin{abstract}
ABSTRAK - Terbatasnya perangkat elektronik untuk penyandang tunanetra yang dapat membantu mereka dalam mempelajari dan menghafalkan al-Qur'an mendorong peneliti untuk merancang perangkat elektronik al-Qur'an Player untuk penyandang tunanetra. Perangkat elektronik tersebut dirancang dengan memanfaatkan mikrokontroler ATMega128 sebagai unit pengontrol utama dan modul DFPlayer sebagai dekoder untuk mengubah dokumen digital ke dalam audio. Seluruh surah maupun ayat al-Qur'an dalam format mp3 tersimpan pada kartu memori yang akan dibaca oleh modul DFPlayer. Perangkat al-Qur'an player diharapkan dapat memudahkan penyandang tunanetra dalam mempelajari pelafalan al-Qur'an dengan baik dan benar.
\end{abstract}

Kata Kunci - al-Qur'an Player; Tunanetra; DFPlayer mini; Mikronkontroler ATMega128

\section{PENDAhuluan}

Al-Qur'an merupakan kitab suci umat Islam dan menjadi pedoman untuk setiap muslim dalam menjalankan kehidupan di dunia. Oleh karena itu, setiap muslim, tak terkecuali penyandang tunanetra, sangat perlu memiliki kemampuan untuk membaca dan memahaminya serta mengamalkannya dalam kehidupan sehari-hari. Selain itu, al-Qur'an juga memiliki keistimewaan untuk dihafalkan oleh setiap muslim karena dalam ajaran Islam sangat besar faedah bagi seorang muslim yang memiliki hafalan al-Qur'an. Salah satu penelitian menyebutkan bahwa al-Qur'an bisa menjadi alat untuk meditasi, mengurangi stres dan berada dalam kondisi istirahat (menenangkan pikiran) dan juga meningkatkan prestasi belajar [1], [2], [3].

Perkembangan teknologi digital memiliki peran dalam membantu setiap muslim agar dapat mempelajari atau mendengarkan cara melafalkan alQur'an dengan baik dan benar. Pada penelitian sebelumnya, peneliti pernah merancang suatu perangkat al-Qur'an braille elektronik [4]. Penelitian ini dimaksudkan untuk mengatasi terbatasnya kesediaan al-Qur'an braille cetak dan juga kemudahan untuk dibawa-bawa. Namun, perangkat tersebut sulit untuk direalisasikan karena harga komponen yang cukup mahal. Hadirnya dokumendokumen audio (.mp3) maupun video (.mp4) yang merupakan rekaman-rekaman para imam di mesjidil Haram maupun Masjid Nabawi yang fasih dalam membaca al-Qur'an sesuai dengan kaidah 
pembacaannya, telah memberikan alternatif dan juga pilihan bagi setiap muslim untuk dapat mempelajari cara membaca hingga menghafalkan al-Qur'an dengan menirukan lantunan para imam mesjid tersebut. Namun, perkembangan teknologi ini belum dapat dirasakan secara optimal oleh para penyandang tunanetra yang memiliki keterbatasan dalam penglihatan sehingga sangat kesulitan untuk dapat menggunakan perangkat teknologi tersebut dengan sempurna. Adapun media yang tersedia saat ini adalah berupa al-Qur'an braille cetak yang jumlahnya masih sangat terbatas.

Pada penelitian sebelumnya, peneliti telah merancang sebuah model perangkat al-Qur'an Player per ayat untuk membantu penyandang tunanetra agar mendengarkan lantunan ayat alQur'an sesuai dengan ayat-ayat yang diinginkan [5]. Namun, perangkat yang dirancang tersebut masih memiliki keterbatasan, salah satunya adalah belum dapat melantunkan sejumlah ayat-ayat tertentu secara berurutan dan juga masih ditemukannya ayat yang tidak sesuai dengan pilihan dikarenakan keterbatasan pada komponen penyimpan lantunan ayat-ayat al-Qur'an. Oleh karena ini, pada penelitian ini dilakukan penambahan fitur dari perangkat sebelumnya dan penggunaan komponen-komponen yang mendukung perangkat agar dapat berfungsi dengan baik.

\section{METODE DAN BAHAN}

Metoda perancangan yang dilakukan adalah metoda eksperimental. Perancangan yang dilakukan terdiri dari perancangan perangkat keras dan perancangan perangkat lunak.

\subsection{Perancangan Perangkat Keras}

Diagram blok perangkat keras secara keseluruhan ditunjukkan pada Gambar 1.

Pada blok a, Mikrokontroler ATMega128 berfungsi sebagai unit pengontrol setiap komponen yang digunakan pada perangkat al-Qur'an Player, yaitu limit switch, modul audio DFPlayer, kartu memori dan LCD 16x2. Mikrokontroler ATMega128 adalah mikrokontroler low power microchip 8-bit AVR RISC yang menggabungkan $128 \mathrm{~KB}$ memori flash yang dapat diprogram, SRAM 4KB, EEPROM 4KB [6]. Tabel 1. menunjukkan konfigurasi pin-pin yang digunakan pada mikrokontroler ATMega128.

Pada blok b, modul Audio DFPlayer digunakan modul DFR0299 [7] sebagai dekoder audio untuk mengubah dokumen audio digital ke dalam format suara. Dokumen audio yang digunakan adalah dokumen audio dengan ekstensi .mp3.

Tabel 1. Konfigurasi pin-pin Mikrokontroler

\begin{tabular}{cccl}
\hline Port & Pin & No Pin & \multicolumn{1}{c}{ Fungsi } \\
\hline A & 0 & 51 & Tombol 1 pada braille \\
& 1 & 50 & Tombol 2 pada braille \\
& 2 & 49 & Tombol 3 pada braille \\
& 3 & 48 & Tombol 4 pada braille \\
& 4 & 47 & Tombol 5 pada braille \\
& 5 & 46 & Tombol 6 pada braille \\
\hline C & 0 & 35 & Tombol Clear \\
& 1 & 36 & Tombol Validasi huruf \\
& 2 & 37 & Tombol Play \\
& 7 & 42 & Busy \\
\hline D & 0 & 25 & RS LCD \\
& 1 & 26 & RD LCD \\
& 2 & 27 & EN LCD \\
& 4 & 29 & Bit 4 LCD \\
& 5 & 30 & Bit 5 LCD \\
& 6 & 31 & Bit 6 LCD \\
& 7 & 32 & Bit 7 LCD \\
\hline E & 0 & 2 & Rx \\
& 1 & 3 & Tx \\
\hline
\end{tabular}

Pada modul ini tersedia slot kartu SD untuk membaca dokumen ayat-ayat al-Qur'an dalam

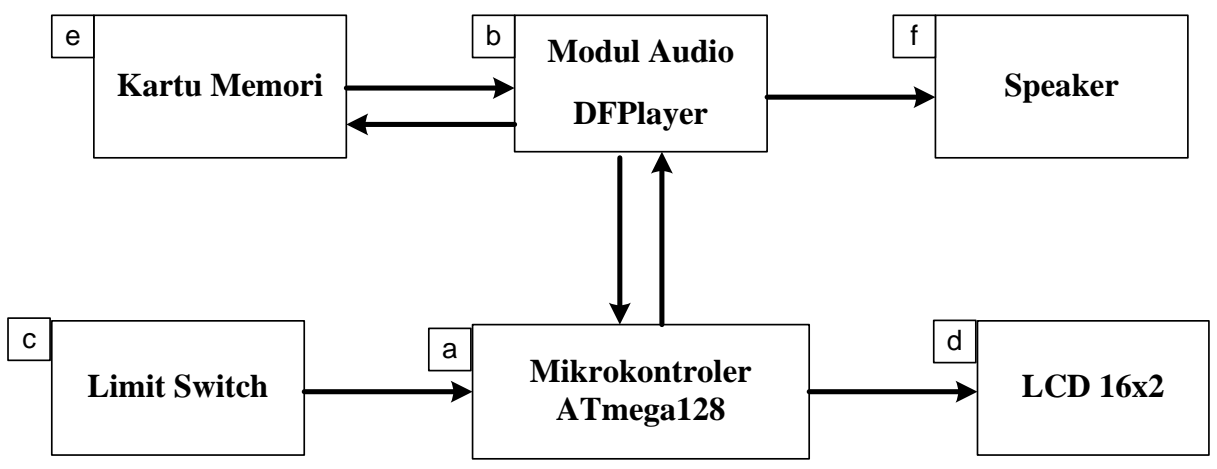

Gambar 1. Diagram blok perangkat keras. 
format mp3 yang telah disimpan dalam kartu SD. Selain itu, pada modul ini juga terdapat IC dekoder audio yang dapat mengubah data audio berformat mp3, wma, wav maupun mid menjadi data sinyal suara yang dapat didengar melalui speaker maupun earphone. Modul audio DFPlayer dan konfigurasi pinpin yang digunakan ditunjukkan pada Gambar 2 dan Tabel 2.

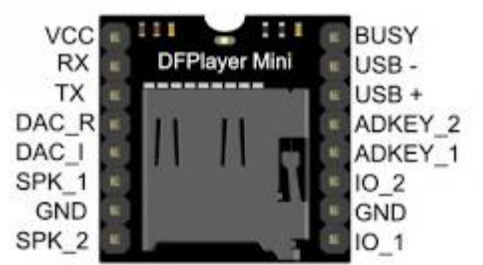

Gambar 2. Modul Audio DFPlayer [7]

Tabel 2. Konfigurasi pin modul DFPlayer Mini [4].

\begin{tabular}{ccl}
\hline No & Nama & \multicolumn{1}{c}{ Deskripsi } \\
\hline 1 & Vcc & Input Voltage \\
2 & RX & UART serial input \\
3 & TX & UART serial output \\
4 & DAC_R & Audio output right channel \\
5 & DAC_L & Audio output left channel \\
6 & SPK2 & Speaker \\
7 & GND & Ground \\
8 & SPK1 & Speaker \\
9 & IO1 & Trigger port 1 \\
10 & GND & Ground \\
11 & IO2 & Trigger port 2 \\
12 & ADKEY1 & AD Port 1 \\
13 & ADKEY2 & AD Port 2 \\
14 & USB+ & USB+ DP \\
15 & USB- & USB- DM \\
16 & BUSY & Playing Status \\
\hline
\end{tabular}

Pada blok c, Limit Switch digunakan sebagai masukan angka yang akan diolah mikrokontroler sehingga menghasilkan suara pada audio dan tampilan pada LCD 16x2. Pengaturan limit switch pada alat berada pada mikrokontroler ATmega128 menggunakan 9 pin I/O, yaitu pin A0 - A5 sebagai I/O tombol kode braille, pin C0 sebagai tombol clear, pin C1 sebagai tombol validasi angka dan pin C2 sebagai tombol play. Rangkaian skematik limit switch ini ditunjukkan pada Gambar 3. Rancangan ini mengikuti rancangan peneliti pada penelitian sebelumnya [8].

Pada blok d, LCD 16x2 merupakan modul penampil elektronik yang digunakan untuk menampilkan kode surat atau ayat yang dimasukkan dari limit switch berdasarkan susunan braille. LCD 16x2 hanya digunakan digunakan untuk memeriksa apakah masukan yang diberikan benar atau salah. Pemeriksaan ini dilakukan oleh orang yang awas. LCD ini memiliki kemampuan untuk menampilkan 32 karakter. Mikrokontroler akan mengakses LCD menggunakan mode pengaturan 4 jalur data sesuai dengan pustaka yang tersedia pada CodeVisionAVR. Gambar 4 menunjukkan skema konfigurasi pin-pin pada LCD $16 \times 2$.

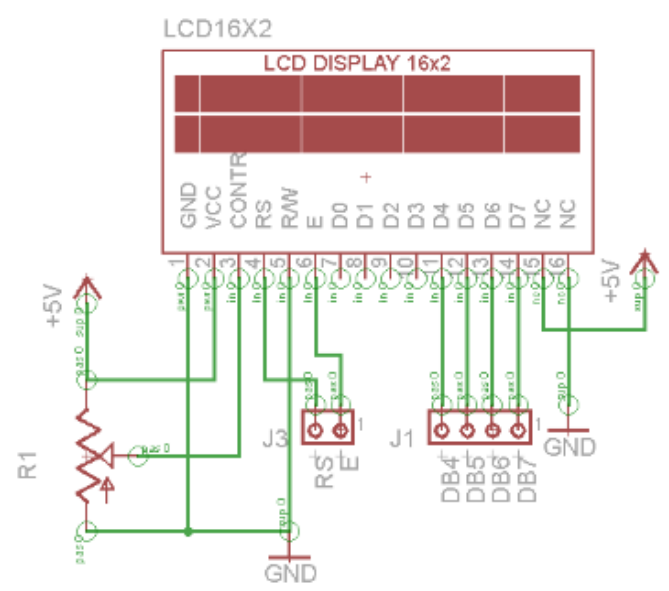

Gambar 4. Konfigurasi pin-pin LCD 16×2

Pada blok e, Kartu Memori berfungsi sebagai penyimpan informasi digital yang menggunakan

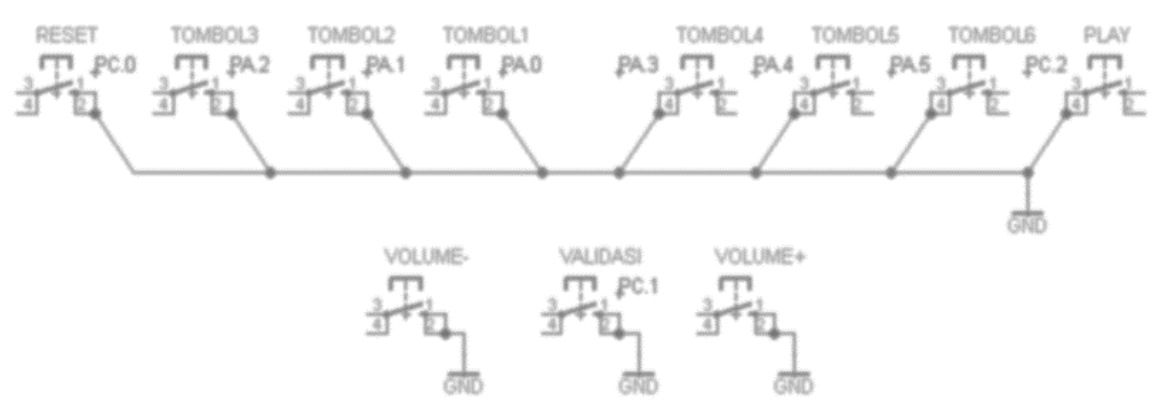

Gambar 3. Rangkaian skematik Limit Switch. 
perangkat memori flash sebagai media penyimpanannya. Kartu memori ini digunakan untuk menyimpan seluruh dokumen ayat-ayat alQur'an dalam format $m p 3$.

Pada blok $f$, Speaker berfungsi sebagai keluaran suara dari modul audio. Ayat-ayat al-Qur'an yang dipilih oleh pengguna akan dilantunkan melalui speaker.

\subsection{Perancangan Perangkat Lunak}

Pada perancangan perangkat lunak dilakukan untuk mengatur alur program pada mikrokontroler agar dapat mengolah data. Gambar 5 menunjukkan diagram alir pada mikrokontroler.

Perangkat lunak ini berfungsi untuk mengendalikan keseluruhan sistem dari alat. Perangkat lunak ini merupakan program yang akan disimpan pada mikrokontroler sebagai unit pengontrol utama. Pada perancangan digunakan software CodeVisionAVR [2.05.3] dengan bahasa yang digunakan yaitu bahasa $C$.

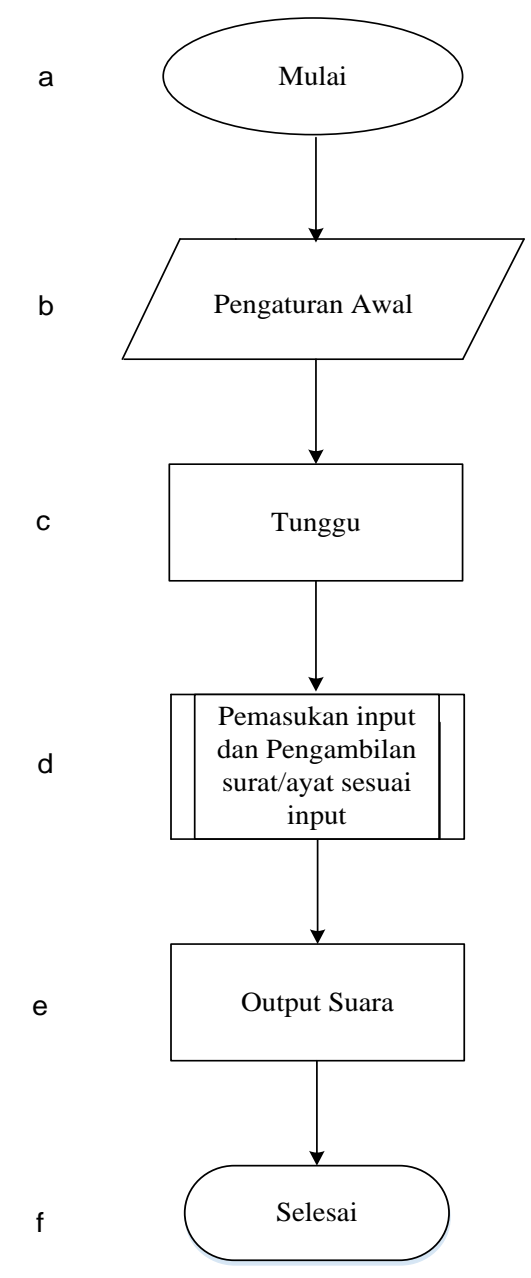

Gambar 5. Diagram alir program utama mikrokontroler

Keterangan diagram alir program utama:

a. Mulai, yaitu proses ketika alat dinyalakan b. Pengaturan awal, yaitu pengaturan inisialisasi variabel-variabel serta pin-pin yang digunakan.

c. Tunggu, yaitu waktu tunggu yang digunakan agar modul DFPlayer siap menerima perintahperintah dari mikrokontroler.

d. Pemasukan input dan pengambilan surat/ayat sesuai input, yaitu prosedur pemeriksaan masukan yang diterima oleh mikrokontroler dari limit switch serta pemeriksaan data yang telah disimpan pada sebuah array, yang kemudian data tersebut diambil berdasarkan kode surat dan ayat, dengan menampilkannya ke LCD serta menyimpan masukan tersebut di sebuah array yang sudah diinisialisasi sebelumnya.

e. Output suara, yaitu hasil dari prosedur pemeriksaan akan menghasilkan data, kemudian data itu dikirimkan dari mikrokontroler ke modul DFPlayer, kemudian data tersebut diproses oleh modul DFPlayer agar menghasilkan keluaran suara.

f. Selesai, yaitu proses akhir dan mengulang ketika alat digunakan.

Proses pembacaan masukan dan pengambilan surat surat/ayat sesuai masukan ditunjukkan dalam diagram alir pada Gambar 6. Berikut keterangan diagram alir prosedur pembacaan masukan dan pengambilan surat/ayat sesuai masukan, diantaranya:

a. Mulai, yaitu memulai pengolahan prosedur dengan masukan penekanan limit switch.

b. Pemeriksaan jenis masukan.

1. Pemeriksaan masukan karakter ' ${ }^{\prime \prime}$.

2. Pemeriksaan masukan karakter antara ' 1 ' hingga ' 114 '.

3. Pemeriksaan masukan karakter antara ' 1 ' hingga ' 286 '.

4. Pemeriksaan masukan karakter ' - '.

5. Pemeriksaan masukan karakter antara ' 1 ' hingga '286'. $(y>x ; y=$ ayat akhir, $x=$ ayat awal $)$.

6. Pemeriksaan masukan karakter '\#'.

c. Pemeriksaan nilai variabel surat, ayat atau ayat pilihan:

1. Pemeriksaan variabel surat dengan jumlah keseluruhan ayat al-Qur'an.

2. Pemeriksaan variabel ayat dengan maksimal jumlah ayat pada surat.

3. Pemeriksaan variabel pemilihan ayat dengan maksimal jumlah ayat pada surat.

d. Pencarian data berdasarkan jenis masukan.

1. Pencarian data untuk per surat

2. Pencarian data untuk per ayat 
Hidayat \& L Nurjanah

Komputika, Vol. 7, No. 2, Oktober 2018

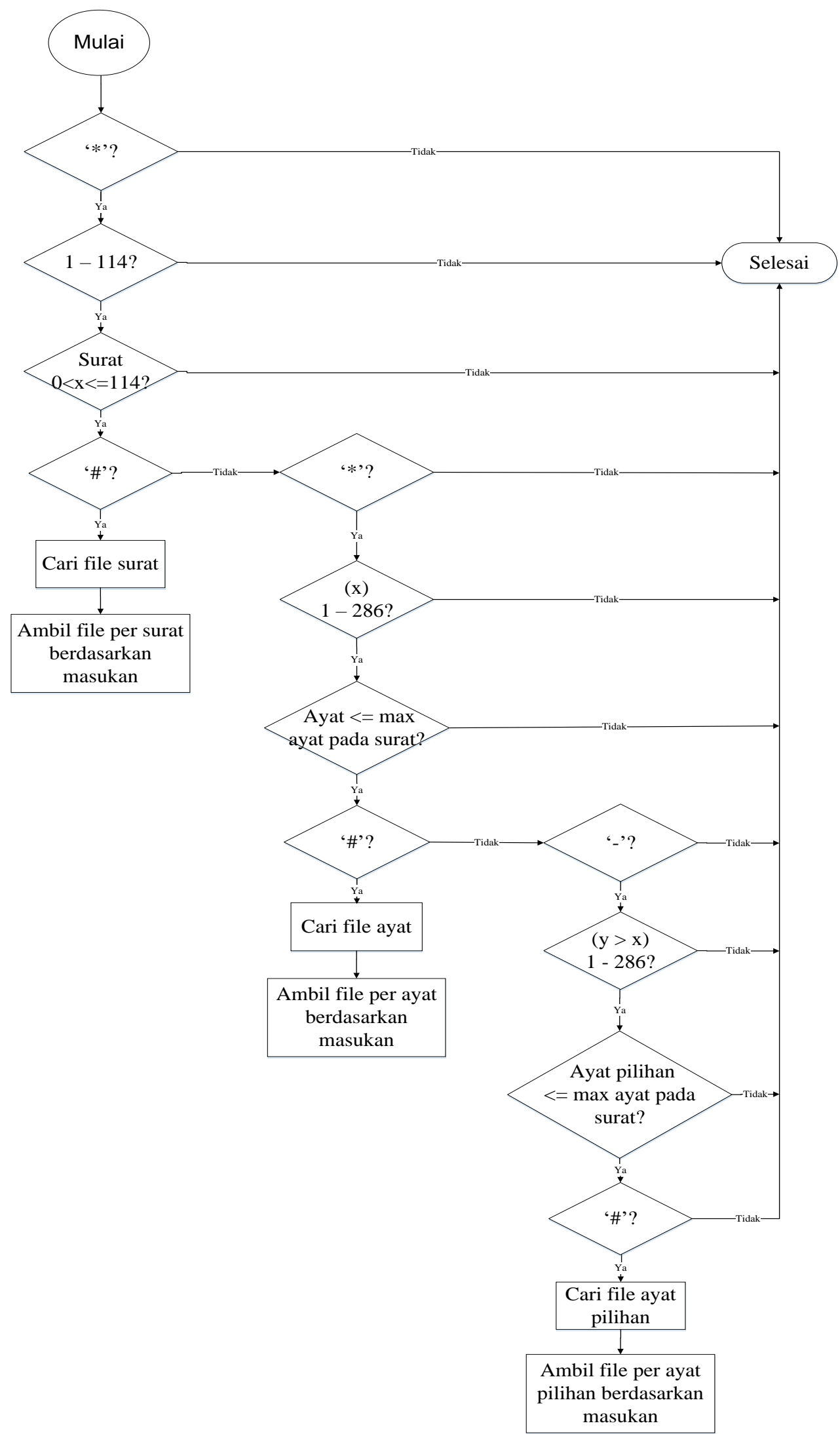

Gambar 6. Diagram alir dari prosedur pemasukan input dan pengambilan surat/ayat sesuai masukan 
e. Pengambilan data berdasarkan jenis masukan.

1. Pengambilan data untuk per surat

2. Pengambilan data untuk per ayat

3. Pengambilan data untuk ayat pilihan

f. Proses akhir dan mengulang ketika alat digunakan.

\section{HASIL DAN PEMBAHASAN}

Implementasi perancangan perangkat keras dan bentuk fisik perangkat yang dirancang diperlihatkan pada Gambar 7.

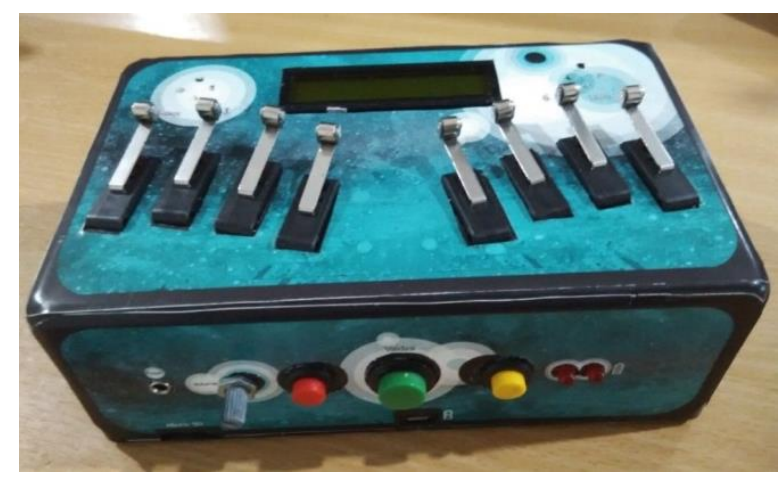

Gambar 7. Tampilan Akhir Perangkat

\subsection{Pengujian}

Pengujian dilakukan untuk mengetahui apakah alat atau sistem berfungsi dengan benar atau tidak. Pada penelitian ini dilakukan 4 pengujian, yaitu pengujian pemilihan masukan per surat, pengujian pemilihan masukan per ayat, pengujian pemilihan masukan ayat pilihan dan pengujian dengan masukan yang salah baik itu per surat maupun per ayat.

\section{A. Pengujian masukan per surat}

Pada pengujian per surat, sistem harus dapat melantunkan ayat-ayat dari surat yang dipilih secara lengkap. Pada Tabel 3. dalam lampiran memperlihatkan sejumlah masukan nomor-nomor surat pada perangkat. Hasil pengujian pada Tabel 3. menunjukkan bahwa sistem dapat melantunkan setiap surat yang dipilih dengan benar.

\section{B. Pengujian masukan per ayat}

Pada pengujian per ayat, sistem harus dapat melantunkan ayat-ayat yang dipilih. Tabel 4 . memperlihatkan sejumlah masukan ayat-ayat yang dipilih untuk dilantunkan oleh perangkat. Hasil pengujian pada Tabel 4. menunjukkan bahwa sistem dapat melantunkan ayat-ayat yang dipilih dengan benar.

\section{Pengujian masukan rentang ayat}

Pada pengujian rentang ayat, sistem harus dapat melantunkan ayat-ayat secara berurutan sesuai rentang yang dimasukkan. Tabel 5. Menampilkan sejumlah masukan rentang ayat yang dimasukkan pada sistem untuk dilantunkan oleh perangkat. Hasil pengujian pada Tabel 5. menunjukkan bahwa sistem dapat melantunkan ayat-ayat sesuai rentang yang dipilih dengan benar.

Tabel 4. Hasil pengujian masukan per ayat

\begin{tabular}{cccc}
\hline No & Kode & Terlantunkan & Sesua \\
\hline 1 & $* 1 * 2 \#$ & Ya & Ya \\
2 & $* 1 * 4 \#$ & Ya & Ya \\
3 & $* 3 * 5 \#$ & Ya & Ya \\
4 & $* 3 * 10 \#$ & Ya & Ya \\
5 & $* 6 * 11 \#$ & Ya & Ya \\
6 & $* 8 * 7 \#$ & Ya & Ya \\
7 & $* 8 * 10 \#$ & Ya & Ya \\
8 & $* 18 * 15 \#$ & Ya & Ya \\
9 & $* 18 * 105 \#$ & Ya & Ya \\
10 & $* 25 * 4 \#$ & Ya & Ya \\
11 & $* 25 * 25 \#$ & Ya & Ya \\
12 & $* 65 * 8 \#$ & Ya & Ya \\
13 & $* 65 * 12 \#$ & Ya & Ya \\
14 & $* 80 * 12 \#$ & Ya & Ya \\
15 & $* 80 * 22 \#$ & Ya & Ya \\
16 & $* 80 * 41 \#$ & Ya & Ya \\
17 & $* 90 * 1 \#$ & Ya & Ya \\
18 & $* 90 * 10 \#$ & Ya & Ya \\
19 & $* 90 * 20 \#$ & Ya & Ya \\
20 & $* 100 * 5 \#$ & Ya & Ya \\
\hline
\end{tabular}

Tabel 5. Hasil pengujian rentang ayat

\begin{tabular}{cccc}
\hline No & Kode & Terlantunkan & Sesuai \\
\hline 1 & $* 1 * 1-3 \#$ & Ya & Ya \\
2 & $* 2 * 9-14 \#$ & Ya & Ya \\
3 & $* 3 * 15-25 \#$ & Ya & Ya \\
4 & $* 4 * 99-110 \#$ & Ya & Ya \\
5 & $* 5 * 20-30 \#$ & Ya & Ya \\
6 & $* 21 * 10-12 \#$ & Ya & Ya \\
7 & $* 22 * 70-75 \#$ & Ya & Ya \\
8 & $* 23 * 111-118 \#$ & Ya & Ya \\
9 & $* 24 * 40-60 \#$ & Ya & Ya \\
10 & $* 25 * 1-20 \#$ & Ya & Ya \\
11 & $* 41 * 10-18 \#$ & Ya & Ya \\
12 & $* 42 * 1-30 \#$ & Ya & Ya \\
13 & $* 43 * 80-88 \#$ & Ya & Ya \\
14 & $* 44 * 15-25 \#$ & Ya & Ya \\
15 & $* 45 * 30-35 \#$ & Ya & Ya \\
16 & $* 61 * 5-10 \#$ & Ya & Ya \\
17 & $* 62 * 8-11 \#$ & Ya & Ya \\
18 & $* 63 * 1-11 \#$ & Ya & Ya \\
19 & $* 64 * 12-18 \#$ & Ya & Ya \\
20 & $* 65 * 4-8 \#$ & Ya & Ya \\
\hline
\end{tabular}




\section{Pengujian masukan yang salah}

Pada pengujian ini dilakukan pengujian dengann memasukkan nomor surat maupun nomor ayat yang tidak terdaftar. Tabel 6. Menampilkan sejumlah masukan yang tidak termasuk dalam daftar nomor surat dan ayat.

Tabel 6. Hasil pengujian masukan yang salah

\begin{tabular}{cccc}
\hline No & Kode & $\begin{array}{c}\text { Terlantunka } \\
\text { n }\end{array}$ & Sesuai \\
\hline 1 & ${ }^{*} \#$ & Tidak & Ya \\
2 & $* 1234 \#$ & Tidak & Ya \\
3 & $* * 12 \#$ & Tidak & Ya \\
4 & $* 1101 \#$ & Tidak & Ya \\
5 & $* 0010 \#$ & Tidak & Ya \\
6 & $* 1111 \#$ & Tidak & Ya \\
7 & $* * \#$ & Tidak & Ya \\
8 & $* 115 \#$ & Tidak & Ya \\
9 & $* 120 \#$ & Tidak & Ya \\
10 & $* 150 \#$ & Tidak & Ya \\
11 & $* 200 \#$ & Tidak & Ya \\
12 & $* 500 \#$ & Tidak & Ya \\
13 & $* 700 \#$ & Tidak & Ya \\
14 & $* 900 \#$ & Tidak & Ya \\
15 & $* 0006 \#$ & Tidak & Ya \\
16 & $* 0200 \#$ & Tidak & Ya \\
17 & $* 725 \#$ & Tidak & Ya \\
18 & $* 1011 \#$ & Tidak & Ya \\
19 & $* 1120 \#$ & Tidak & Ya \\
20 & $* 4 * 177 \#$ & Tidak & Ya \\
21 & $* 10 * 110 \#$ & Tidak & Ya \\
22 & $* 29 * 70 \#$ & Tidak & Ya \\
23 & $* 50 * 50 \#$ & Tidak & Ya \\
24 & $* 65 * 13 \#$ & Tidak & Ya \\
25 & $* 84 * 30 \#$ & Tidak & Ya \\
\hline & & &
\end{tabular}

Berdasarkan hasil pengujian, setiap mulai dinyalakan dibutuhkan waktu sekitar 3 sampai dengan 4 detik untuk modul DFPlayer membaca dokumen audio yang terdapat pada kartu memori. Lama waktu persiapan modul audio player disebabkan banyaknya berkas yang harus dikelola oleh modul DFPlayer, yaitu berkisar 6.353 lebih dokumen audio berformat mp3. Namun,waktu pemanggilan surat maupun ayat hampir tidak ada jeda waktu yang diperlukan sepertinya hanya pada perangkat penelitian sebelumnya[3].

Tingkat keberhasilan perangkat dalam melantunkan surat maupun ayat yang tersimpan pada memori adalah sebesar $100 \%$.

\section{KeSIMPULAN}

Berdasarkan hasil pengujian dan analisis perangkat keras maupun algoritma perangkat lunak diperoleh beberapa kesimpulan sebagai berikut:

- Sistem yang dirancang pada alat telah berfungsi dengan benar, modul audio DFPlayer dapat bekerja dengan baik sebagai dekoder audio dan data pada kartu memori SD dapat diakses oleh Modul DFPlayer.

- Program yang telah dibuat berhasil membedakan kode masukan per surat, per ayat dan ayat pilihan sehingga didapatkan pembacaan satu surat penuh, satu ayat penuh dan beberapa ayat pilihan penuh.

Adapun saran untuk pengembangan penelitian ini selanjutnya adalah memperbaiki keluaran suara baik pada speaker maupun headset/earphone karena masih kurang baik serta menambahkan fitur pause dan replay.

\section{UCAPAN TERIMA KASIH}

Peneliti mengucapkan terima kasih kepada Universitas Komputer Indonesia yang telah memfasilitasi penelitian ini.

\section{DAFTAR PUSTAKA}

[1] N. Fazrena, N. Humaimi, and N. Aini, "Modeling brain activities during reading working memory task: Comparison between reciting Quran and reading book," Procedia - Soc. Behav. Sci., vol. 97, pp. 83-89, 2013.

[2] Y. Masduki, "Implikasi Psikologis Bagi Penghafal Al-Qur'an," J. Medina-Te, vol. 18, no. 1, pp. 18-35, 2018.

[3] M. Hidayat, Ginanjar, "Aktivitas Menghafal AlQur'an dan Pengaruhnya terhadap Prestasi Akademik Mahasiswa," J. Edukasi Islam. J. Pendidik. Islam, vol. 06, no. 11, 2017.

[4] H. Hidayat and A. Nugraha, "Perancangan Perangkat Elektronik Media Pembelajaran Iqra dalam Kode Braille," J. Sist. Komput., vol. 5, no. 2, pp. 65-71, 2015.

[5] H. Hidayat and F. Rahmatullah, "Rancang Bangun AL-Qur'an Audio Player by Ayah (QuPA) 1.0," Maj. Ilm. Unikom, vol. 12, no. 1, pp. 53-60, 2014.

[6] Microchip.com. (2019). ATmega128 - 8-bit AVR Microcontrollers. [online] Available at: https://www.microchip.com/wwwproducts/en/ATme ga128 [Accessed 8 Feb. 2019].

[7] DFPlayer - A Mini MP3 Player [internet]. 2014. Available form: https://www.dfrobot.com/wiki/ index.php/DFPlayer_Mini_SKU:DFR0299

[8] H. Hidayat and A. Prafanto, "Electronic Voice for Set of the Syllables from Braille Code Input based on Microcontroller," Indian J. Sci. Technol., vol. 9, no. December, pp. 1-8, 2016. 
Hidayat \& L Nurjanah

Komputika, Vol. 7, No. 2, Oktober 2018

\section{LAMPIRAN}

Tabel 3. Hasil pengujian masukan per ayat

\begin{tabular}{|c|c|c|c|}
\hline No & Surat & Kode & Terlantunkan \\
\hline 1 & Al-Fatihah & $* 1 \#$ & $\mathrm{Ya}$ \\
\hline 2 & Al-Baqarah & *2\# & $\mathrm{Ya}$ \\
\hline 3 & Ali 'Imran & $* 3 \#$ & $\mathrm{Ya}$ \\
\hline 4 & An-Nisa' & $* 4 \#$ & $\mathrm{Ya}$ \\
\hline 5 & Al-Ma'idah & $* 5 \#$ & $\mathrm{Ya}$ \\
\hline 6 & Al-An'am & *6\# & $\mathrm{Ya}$ \\
\hline 7 & Al-A'raf & *7\# & $\mathrm{Ya}$ \\
\hline 8 & Al-Anfal & *8\# & $\mathrm{Ya}$ \\
\hline 9 & At-Taubah & *9\# & $\mathrm{Ya}$ \\
\hline 10 & Yunus & $* 10 \#$ & $\mathrm{Ya}$ \\
\hline 11 & Hud & *11\# & $\mathrm{Ya}$ \\
\hline 12 & Yusuf & $* 12 \#$ & $\mathrm{Ya}$ \\
\hline 13 & Ar-Ra'd & $* 13 \#$ & $\mathrm{Ya}$ \\
\hline 14 & Ibrahim & $* 14 \#$ & $\mathrm{Ya}$ \\
\hline 15 & Al-Hijr & $* 15 \#$ & $\mathrm{Ya}$ \\
\hline 16 & An-Nahl & $* 16 \#$ & $\mathrm{Ya}$ \\
\hline 17 & Al-Isra' & $* 17 \#$ & $\mathrm{Ya}$ \\
\hline 18 & Al-Kahfi & $* 18 \#$ & $\mathrm{Ya}$ \\
\hline 19 & Maryam & $* 19 \#$ & $\mathrm{Ya}$ \\
\hline 20 & Ta-Ha & $* 20 \#$ & $\mathrm{Ya}$ \\
\hline 21 & Al-Anbiya & *21\# & $\mathrm{Ya}$ \\
\hline 22 & Al-Hajj & $* 22 \#$ & $\mathrm{Ya}$ \\
\hline 23 & Al-Mu'minun & $* 23 \#$ & $\mathrm{Ya}$ \\
\hline 24 & An-Nur & $* 24 \#$ & $\mathrm{Ya}$ \\
\hline 25 & Al-Furqan & $* 25 \#$ & $\mathrm{Ya}$ \\
\hline 26 & Asy-Syu'ara' & *26\# & $\mathrm{Ya}$ \\
\hline 27 & An-Naml & $* 27 \#$ & $\mathrm{Ya}$ \\
\hline 28 & Al-Qashash & $* 28 \#$ & $\mathrm{Ya}$ \\
\hline 29 & Al-'Ankabut & $* 29 \#$ & $\mathrm{Ya}$ \\
\hline 30 & Ar-Rum & *30\# & $\mathrm{Ya}$ \\
\hline 31 & Luqman & *31\# & $\mathrm{Ya}$ \\
\hline 32 & As-Sajdah & *32\# & $\mathrm{Ya}$ \\
\hline 33 & Al-Ahzab & *33\# & $\mathrm{Ya}$ \\
\hline 34 & Saba' & *34\# & $\mathrm{Ya}$ \\
\hline 35 & Fatir & $* 35 \#$ & $\mathrm{Ya}$ \\
\hline 36 & Ya-Sin & $* 36 \#$ & $\mathrm{Ya}$ \\
\hline 37 & As-Saffat & *37\# & $\mathrm{Ya}$ \\
\hline 38 & Shad & $* 38 \#$ & $\mathrm{Ya}$ \\
\hline 39 & Az-Zumar & *39\# & $\mathrm{Ya}$ \\
\hline 40 & Al-Mu'min & $* 40 \#$ & $\mathrm{Ya}$ \\
\hline 41 & Al-Fushilat & $* 41 \#$ & $\mathrm{Ya}$ \\
\hline 42 & Asy-Syura & $* 42 \#$ & $\mathrm{Ya}$ \\
\hline 43 & Az-Zukhruf & $* 43 \#$ & $\mathrm{Ya}$ \\
\hline 44 & Ad-Dukhan & $* 44 \#$ & $\mathrm{Ya}$ \\
\hline 45 & Al-Jasiyah & $* 45 \#$ & $\mathrm{Ya}$ \\
\hline 46 & Al-Ahqaaf & $* 46 \#$ & $\mathrm{Ya}$ \\
\hline 47 & Muhammad & $* 47 \#$ & $\mathrm{Ya}$ \\
\hline 48 & Al-Fath & $* 48 \#$ & $\mathrm{Ya}$ \\
\hline 49 & Al-Hujuraat & *49\# & $\mathrm{Ya}$ \\
\hline 50 & Qaf & $* 50 \#$ & $\mathrm{Ya}$ \\
\hline 51 & Az-Zariyat & $* 51 \#$ & $\mathrm{Ya}$ \\
\hline 52 & Ath-Thuur & $* 52 \#$ & $\mathrm{Ya}$ \\
\hline 53 & An-Najm & $* 53 \#$ & $\mathrm{Ya}$ \\
\hline 54 & Al-Qamar & *54\# & $\mathrm{Ya}$ \\
\hline 55 & Ar-Rahman & $* 55 \#$ & $\mathrm{Ya}$ \\
\hline 56 & Al-Waqi'ah & $* 56 \#$ & $\mathrm{Ya}$ \\
\hline 57 & Al-Hadiid & $* 57 \#$ & $\mathrm{Ya}$ \\
\hline
\end{tabular}

\begin{tabular}{|c|c|c|c|}
\hline No & Surat & Kode & Terlantunkan \\
\hline 58 & Al-Mujadilah & $* 58 \#$ & $\mathrm{Ya}$ \\
\hline 59 & Al-Hasyr & *59\# & $\mathrm{Ya}$ \\
\hline 60 & Al-Mumtahanah & *60\# & $\mathrm{Ya}$ \\
\hline 61 & Ash-Shaff & *61\# & $\mathrm{Ya}$ \\
\hline 62 & Al-Jumuah & $* 62 \#$ & $\mathrm{Ya}$ \\
\hline 63 & Al-Munafiqun & $* 63 \#$ & $\mathrm{Ya}$ \\
\hline 64 & At-Taghabun & $* 64 \#$ & $\mathrm{Ya}$ \\
\hline 65 & At-Talaq & $* 65 \#$ & $\mathrm{Ya}$ \\
\hline 66 & At-Tahriim & *66\# & $\mathrm{Ya}$ \\
\hline 67 & Al-Mulk & *67\# & $\mathrm{Ya}$ \\
\hline 68 & Al-Qalam & *68\# & $\mathrm{Ya}$ \\
\hline 69 & Al-Haqqah & *69\# & $\mathrm{Ya}$ \\
\hline 70 & Al-Ma'arij & $* 70 \#$ & $\mathrm{Ya}$ \\
\hline 71 & Nuh & $* 71 \#$ & $\mathrm{Ya}$ \\
\hline 72 & Al-Jinn & *72\# & $\mathrm{Ya}$ \\
\hline 73 & Al-Muzammil & *73\# & $\mathrm{Ya}$ \\
\hline 74 & Al-Muddassir & $* 74 \#$ & $\mathrm{Ya}$ \\
\hline 75 & Al-Qiyamah & $* 75 \#$ & $\mathrm{Ya}$ \\
\hline 76 & Al-Insan & $* 76 \#$ & $\mathrm{Ya}$ \\
\hline 77 & Al-Mursalat & $* 77 \#$ & $\mathrm{Ya}$ \\
\hline 78 & An-Naba' & $* 78 \#$ & $\mathrm{Ya}$ \\
\hline 79 & An-Naazi'at & *79\# & $\mathrm{Ya}$ \\
\hline 80 & 'Abasa & *80\# & $\mathrm{Ya}$ \\
\hline 81 & At-Takwiir & $* 81 \#$ & $\mathrm{Ya}$ \\
\hline 82 & Al-Infitha & *82\# & $\mathrm{Ya}$ \\
\hline 83 & Al-Muthaffifin & *83\# & $\mathrm{Ya}$ \\
\hline 84 & Al-Insyiqaq & $* 84 \#$ & $\mathrm{Ya}$ \\
\hline 85 & Al-Buruuj & *85\# & $\mathrm{Ya}$ \\
\hline 86 & Ath-Thariq & *86\# & $\mathrm{Ya}$ \\
\hline 87 & Al-A'laa & $* 87 \#$ & $\mathrm{Ya}$ \\
\hline 88 & Al-Ghaasyiah & $* 88 \#$ & $\mathrm{Ya}$ \\
\hline 89 & Al-Fajr & *89\# & $\mathrm{Ya}$ \\
\hline 90 & Al-Balad & *90\# & $\mathrm{Ya}$ \\
\hline 91 & Asy-Syams & *91\# & $\mathrm{Ya}$ \\
\hline 92 & Al-Lail & *92\# & $\mathrm{Ya}$ \\
\hline 93 & Ad-Duha & *93\# & $\mathrm{Ya}$ \\
\hline 94 & Al-Insyirah & *94\# & $\mathrm{Ya}$ \\
\hline 95 & At-Tin & $* 95 \#$ & $\mathrm{Ya}$ \\
\hline 96 & Al-'Alaq & *96\# & $\mathrm{Ya}$ \\
\hline 97 & Al-Qadr & *97\# & $\mathrm{Ya}$ \\
\hline 98 & Al-Bayyinah & $* 98 \#$ & $\mathrm{Ya}$ \\
\hline 99 & Az-Zalzalah & *99\# & $\mathrm{Ya}$ \\
\hline 100 & Al-'Adiyat & $* 100 \#$ & $\mathrm{Ya}$ \\
\hline 101 & Al-Qari'ah & *101\# & $\mathrm{Ya}$ \\
\hline 102 & At-Takaats & *102\# & $\mathrm{Ya}$ \\
\hline 103 & Al-'Ashr & *103\# & $\mathrm{Ya}$ \\
\hline 104 & Al-Humazah & *104\# & $\mathrm{Ya}$ \\
\hline 105 & Al-Fiil & $* 105 \#$ & $\mathrm{Ya}$ \\
\hline 106 & Quraisy & *106\# & $\mathrm{Ya}$ \\
\hline 107 & Al-Ma'un & $* 107 \#$ & $\mathrm{Ya}$ \\
\hline 108 & Al-Kautsar & *108\# & $\mathrm{Ya}$ \\
\hline 109 & Al-Kafirun & *109\# & $\mathrm{Ya}$ \\
\hline 110 & An-Nashr & *110\# & $\mathrm{Ya}$ \\
\hline 111 & Al-Lahab & *111\# & $\mathrm{Ya}$ \\
\hline 112 & Al-Ikhlash & *112\# & $\mathrm{Ya}$ \\
\hline 113 & Al-Falaq & *113\# & $\mathrm{Ya}$ \\
\hline 114 & An-Nas & *114\# & $\mathrm{Ya}$ \\
\hline
\end{tabular}

